\section{Applications for Approval of Higher Training Undertaken in Research Posts}

All psychiatric trainees occupying research posts who wish training gained during this period to count towards a CCST must submit an individual application to the HSTC. Application forms are available from the HSTC Office at the College and must be supported by both the relevant training programme director and postgraduate dean.

Although the regulations have always required applications to be made prospectively, the HSTC has in the past always been flexible in giving consideration to the many applications submitted retrospectively. However, in future applications which are submitted more than six months after commencement in a research post will not be considered. This regulation will be strictly applied with effect from 1 February 1999. In any event, trainees are best advised to apply early since approval is not automatic.

\section{BUPA Foundation Communication Award for 1999}

In association with the Academy of Medical Royal Colleges and the Patients Association, The BUPA Foundation will be supporting the Communication Award 1999. There will be two prizes of $£ 10000$ each, one for work completed by individuals or a group of individuals, and one for work undertaken by a college, institution, hospital, or professional body. Entries must demonstrate an improvement in one of the following: doctor-patient communication, communication between doctors and patients, the communication skills of individual doctors, the methods of transferring information between doctors and patients, and finally, patient information systems. Further information: Lady Nourse, 12 Old Square, Lincoln's Inn, London WC2A 3TX (Telephone: 0171404 0809, Fax: $01718318096)$.

\section{New publications}

Men Behaving Sadly, a new leaflet in the Help is at Hand series, aims to encourage men to recognise their emotional distress and to seek help. The leaflet looks at the signs and symptoms of depression, and at possible reasons why ma are less likely to admit that they need help. Tips on 'Helping Yourself and 'Finding More Help' are given, and there is information on useful contacts as well as a reading list. Individual copies of this leaflet are available from the Royal College of Psychiatrists, 17 Belgrave Square, London SW 1X 8PG (SAE needed) (e-mail: rcpsych @rcpsych.ac.uk; internet website: http: /lwww. rcpsych.ac.uk).

The Health Education Authority has produced a practical guide to help people diagnosed with schizophrenia. Entitled Healthy Living With Schizophrenia, the guide will also prove useful for carers, doctors, psychiatrists and others with an interest in schizophrenia. It covers a wide range of topics, from symptoms and self-help, to medication and the Mental Health Act. It also contains a set of summary cards outlining key questions to ask doctors, a personalised crisis card and sources of further information, including helplines and websites. Further information: Gary Ward, Health Education Authority Press Office (Telephone: 0171413 1998).

The Clinical Effectiveness Project Team (CEPT) at the Royal College of Psychiatrists' Research Unit has produced a series of information sheets focusing on key aspects of clinical effectiveness in mental health. The sheets provide resources and contacts to assist busy professionals within mental health services to access essential information at a glance. Available now, the first three sheets are entitled: Resources available to support clinical effectiveness in mental health services; Training to support clinical effectiveness in mental health services; and Psychiatrists' training and involvement in clinical effectiveness activities: statements from the Royal College of Psychiatrists. Future topics will include national policies for clinical effectiveness and involving service users and carers in audit and guidelines. Priced at $\$ 3.00$ each, copies and further information can be obtained from: Victoria Thomas, Clinical Effectiveness Project Team, College Research Unit, 11 Grosvenor Crescent, London SW1X 7EE (Telephone: 01712352351 ext. 282. Fax: 0171235 2954, e-mail: victoria.thomas@ virgin.net).

Person To Person by Phoebe Caldwell, with Pene Stevens, is the title of a new practical guide on communicating with people whose behaviour is challenging or displays autistic features. Published by Pavillion Publishing, the book explains the techniques developed by the author in her 